\title{
Artículos
}

\section{Evaluación de hemerotecas de prensa digital: indicadores y ejemplos de buenas prácticas}

\author{
Por Javier Guallar y Ernest Abadal
}

\begin{abstract}
Resumen: La gran mayoría de los diarios digitales facilitan el acceso a la información retrospectiva mediante servicios de hemerotecas o archivos de prensa, un producto de notable interés para bibliotecas y otros servicios de información. El objetivo de este estudio es determinar cuáles son los indicadores fundamentales para la evaluación de hemerotecas digitales y, además, señalar ejemplos de buenas prácticas en España para cada uno de ellos. Se propone una relación de veintisiete indicadores agrupados en cuatro grandes apartados (aspectos generales, contenidos, sistema de consulta, y presentación de resultados), se describe cada uno de ellos y se incluye algún ejemplo de buena aplicación. Metodológicamente, se ha partido de la revisión de la bibliografía especializada en evaluación de recursos web, bases de datos y hemerotecas digitales, así como del análisis de hemerotecas de diarios de España y Catalunya. La utilización de estos indicadores puede ser de utilidad para que bibliotecas y otros servicios de información puedan orientar a sus usuarios en la consulta retrospectiva de información de prensa.
\end{abstract}

Palabras clave: Prensa digital, Diarios digitales, Diarios online, Hemerotecas digitales, Archivos de prensa, Sistemas de búsqueda, Evaluación, Recursos web, Bases de datos, España.

Title: Evaluation of digital press archives: indicators and examples of good practice

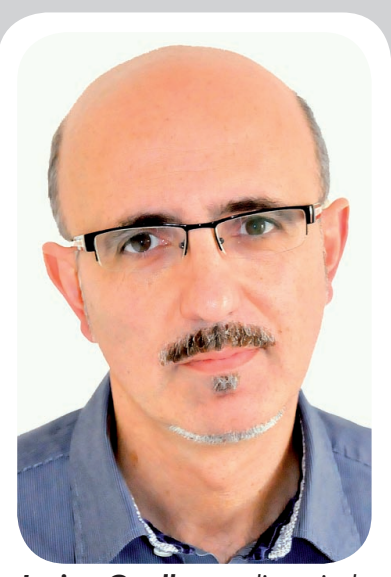

Javier Guallar es licenciado en geografía e historia por la $U B$, en información y documentación por la UOC y DEA en información y documentación por la UB. Es documentalista del diario El periódico de Catalunya, profesor de la Universitat de Barcelona, subdirector de la revista El profesional de la información y coordinador del Anuario ThinkEPI.

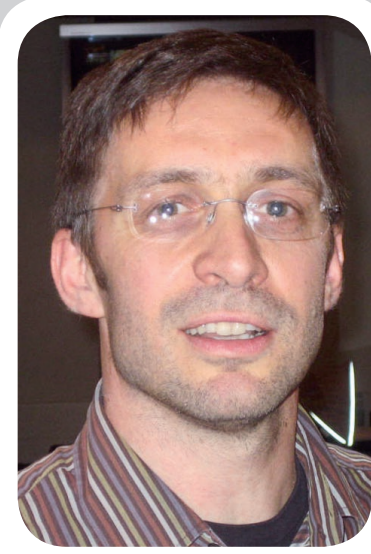

Ernest Abadal es profesor titular de la Facultad de Biblioteconomía y Documentación de la Universitat de Barcelona. Es autor de diversos artículos y monografías sobre publicaciones digitales, director de la revista BiD y codirector del grupo de investigación "Acceso abierto a la ciencia".

http://accesoabierto.net

Abstract: The majority of online newspapers provide access to retrospective information through press archive services, a product of great interest for libraries and other information services. The aim of this study is to identify key indicators for the evaluation of digital press archives and also identify examples of good practices in Spain for each of them. We propose a list of twenty-seven indicators grouped into four main sections (general features, contents, query system, and presentation of results), describe each one and include some examples of successful implementation. Methodologically, the indicators are the result of the review of the literature on evaluating web resources, databases and digital press archives, as well as the analysis of press archive services of newspapers from Spain and Catalonia. The use of these indicators can be useful for libraries and other information services to guide their users in consulting retrospective press information.

Keywords: Digital press, Digital newspapers, Online newspapers, Digital press archives, Search systems, Evaluation, Web resources, Databases, Spain.

Guallar, Javier; Abadal, Ernest. "Evaluación de hemerotecas de prensa digital: indicadores y ejemplos de buenas prácticas”. El profesional de la información, 2009, mayo-junio, v. 18, n. 3, pp. 255-269.

DOI: 10.3145/epi.2009.may.02

\section{Introducción}

La prensa digital es uno de los productos culturales que se ha ido adaptando con mayor celeridad a las novedades y al entorno cambiante de la Web. Estos es- fuerzos no han sido en balde ya que, si atendemos los datos de las encuestas de uso de recursos web, queda bastante claro que la información de actualidad es uno de los contenidos más solicitados. 
Uno de los servicios específicos del entorno digital que los diarios en internet proporcionan a sus usuarios y que los diferencian más claramente de las ediciones impresas es el acceso organizado a contenidos de archivo o hemeroteca.

Estos servicios, que nosotros denominaremos preferentemente con el término "hemerotecas", disponen en muchos casos de sistemas de recuperación que permiten consultar todo tipo de información periodística, ya sea de máxima actualidad o retrospectiva, se trate de las ediciones digitales o de las impresas, y no tan sólo en formato texto sino también fotografías o vídeos.

\section{"Nos parece relevante poder conocer los elementos esenciales que tienen que estar presentes en una buena hemeroteca digital"}

Estas amplias prestaciones que actúan sobre extensas y diversas colecciones constituyen a nuestro entender, uno de los recursos de mayor interés de la prensa digital, no sólo desde el punto de vista del usuario final o no especializado sino también y de manera especial, desde el punto de vista de los propios periodistas, de los investigadores (historiadores, sociólogos, politólogos, etc.) y de los profesionales de centros de información como crais, bibliotecas y, por supuesto, otros servicios de documentación de prensa.

En este contexto de presencia generalizada de hemerotecas de prensa nos parece relevante proponer un análisis que puede poner de manifiesto cuáles son los elementos esenciales que, eventualmente, deberían estar presentes en una buena hemeroteca digital que quiera facilitar el acceso a los contenidos retrospectivos de un diario. Esta clase de análisis puede ayudar a profesionales que, a medio o a corto plazo, deban afrontar proyectos en este campo, ya sea para sistemas de nueva creación o para revisar las funciones de los ya existentes.

\section{Antecedentes}

La bibliografía sobre diarios digitales es muy abundante, también en España, ya desde sus orígenes hace quince años. Sin ánimo de exhaustividad, se pueden citar los trabajos de Díaz-Noci, Salaverría, Meso, Cabrera, Armentia, López-García, Domingo, y un largo etcétera. Dentro de estos trabajos, la bibliografía específica sobre el servicio de hemeroteca es en cambio sustancialmente menor en número.
Esta última es una de las principales referencias de interés para nuestro análisis junto a aquellos trabajos evaluativos cuyo ámbito guarda relación con el nuestro. Efectivamente, los elementos o indicadores que sirven para evaluar la calidad de las hemerotecas de los diarios tienen aspectos particulares de los propios archivos de prensa, pero también comparten otros muchos con las bases de datos web y con los recursos web en general.

Por ello, nos referimos a continuación a las principales referencias que hemos tenido en cuenta en estas tres áreas de estudio diferentes.

En lo que se refiere a evaluación de recursos web en general, destacan las contribuciones de Auer (1999), Hofman y Worsfold (1999), esta última presentada dentro del proyecto europeo DESIRE (Development of a European Service for Information on Research and Education) y, en España, los trabajos de Lluís Codina (2000, 2006) y de Marina Jiménez y Virginia OrtizRepiso (2007). Precisamente en esta obra, las autoras incluyen un capítulo con una revisión bibliográfica muy completa sobre esta cuestión donde se repasan las principales propuestas y se sintetizan los criterios e indicadores más utilizados.

En el caso de las interfaces de consulta de bases de datos web, destacamos dos textos que han abordado el proceso de consulta a bases de datos desde el punto de vista del proceso seguido por el usuario (Marchionini, 1995 y Shneiderman 1997) y también dos textos clásicos en el campo de la usabilidad y la arquitectura de la información (Nielsen, 2000, 2006; Morville; Rosenfeld, 2006). Estos últimos disponen de apartados dedicados a la interfaz de consulta de bases de datos en los cuales se destacan los principales aspectos que tiene que cumplir un buen sitio web de este tipo. A partir de estos precedentes, se presentó una propuesta de indicadores sobre bases de datos (Abadal, 2002).

Por último, se han revisado los estudios específicos sobre análisis y evaluación de hemerotecas de prensa digital. En el ámbito internacional, se pueden señalar los trabajos de Nicola Cowen (2001), que evalúa las sedes web de cinco periódicos aplicando 16 indicadores en tres grandes categorías (contenidos, interactividad y marketing), considerando la hemeroteca digital (Archive) en el apartado de contenidos; y Brunella Longo (2006), que hace un repaso a la presencia de los archivos de prensa italiana en internet y describe sus principales prestaciones.

En España las aportaciones más nutridas proceden del grupo de investigadores de la UAB formado por Eulàlia Fuentes, Alfons González y Àngels Jiménez a las que posteriormente se han incorporado otros autores. Dos de los primeros trabajos de este grupo (Fuentes; González, 1998; Jiménez et al, 1999) tratan con exhaustividad los diarios españoles con presencia en 
internet y analizan algunos indicadores de sus hemerotecas como la cobertura y los operadores del sistema de consulta. En Jiménez et al (2000) se compara una selección de hemerotecas españolas con otras del resto del mundo y se describe la situación en lo que se refiere a España de más de cincuenta diarios digitales. Posteriormente, en Jiménez (2003) se describen la cobertura y las condiciones de suscripción de las hemerotecas de pago disponibles en aquel momento.

Otros autores también se han referido a estas cuestiones. Sería el caso de Rosana López-Carreño (2004), que considera las hemerotecas dentro de su categorización de servicios de la prensa digital en tres grupos (productos informativos, documentales y servicios de valor añadido), como un SVA (servicio de valor añadido) de acceso a la información. En una línea similar, Rosa Martínez-Rubio (2008), realiza un análisis de los diarios digitales valencianos en el que contempla "cinco elementos significativos en la recuperación de la información”, que son: buscador interno, canales rss, hemeroteca o archivo, mapa del web y menú o índice temático. Su análisis es de presencia o ausencia de estos elementos.

Otro tipo de enfoque es el que llevan a cabo García Gómez y González Olivares (2001), que presentan una evaluación de los sistemas de búsqueda de cuatro diarios, realizando diez consultas sobre diez temas y analizando la exhaustividad y precisión en los resultados obtenidos. Este estudio es representativo de una metodología para realizar evaluaciones de sistemas de recuperación de la información a partir de la realización de búsquedas concretas en las que intervienen varios participantes y la valoración de la pertinencia de los resultados.

Finalmente, por nuestra parte, hemos llevado a cabo un análisis de las hemerotecas digitales de la prensa en España y en Catalunya (Abadal y Guallar, 2008) que nos ha permitido poner a prueba una lista de indicadores para la realización de la evaluación.

Los textos comentados hasta ahora pretenden mostrar la situación de las hemerotecas digitales en un momento determinado o su evolución. Aunque la mayoría de ellos utilizan una parrilla de indicadores, no acostumbran a centrarse en su definición ni análisis detallado. En nuestro texto en cambio, tomamos los indicadores como objeto central de estudio y profundizamos en estos elementos que sirven de base para la evaluación. De esta forma pueden ser de utilidad para aquellos profesionales o investigadores que quieran llevar a cabo operaciones de selección de hemerotecas digitales.

\section{Objetivos y metodología}

Situados los antecedentes, el objetivo principal de este trabajo es determinar cuáles son los indicadores fundamentales para la evaluación de hemerotecas digitales y señalar ejemplos de buenas prácticas en España. La propuesta combina por lo tanto aspectos teóricos (indicadores) con otros marcadamente prácticos (casos ejemplares).

Para el establecimiento de la relación de indicadores se ha partido de la revisión de la bibliografía especializada en este asunto (comentada en el apartado anterior) así como del análisis detallado de las hemerotecas digitales de los diarios de mayor difusión en España y en Catalunya (Abadal; Guallar, 2008) ${ }^{1}$. La revisión bibliográfica nos ha permitido contrastar y afianzar mejor nuestra propuesta teórica y el análisis práctico nos ha suministrado los ejemplos de buenas prácticas que acompañan la descripción de cada uno de los indicadores.

Así pues, se trata de un estudio de carácter evaluativo que se basa en el establecimiento de una relación de indicadores que sirvan para determinar la calidad y grado de desarrollo de hemerotecas digitales. El modelo de excelencia que se toma como referencia son las bases de datos comerciales más desarrolladas del sector, como es el caso de Lexis-Nexis y Factiva, de alcance internacional, o de la española Mynews.

\section{http://www.lexisnexis.com/ \\ http://global.factiva.com/ \\ http://www.mynews.es/}

No se trata por lo tanto de una aproximación basada en el análisis de resultados a partir de consultas realizadas en distintas hemerotecas, como ha sido el enfoque del trabajo de García Gómez y González Olivares (2001) antes comentado. Tampoco se ha recurrido a otras metodologías como podrían ser las encuestas de satisfacción de usuarios o el análisis de logs, ampliamente utilizados para el análisis de sistemas de recuperación de información, ya sean bases de datos en general, motores de búsqueda o hemerotecas digitales, como es nuestro caso.

\section{"Los indicadores tienen aspectos particulares de los archivos de prensa, pero también comparten otros muchos con las bases de datos web y con los recursos web en general"}

\section{Indicadores y ejemplos de buenas prácticas}

Se proponen veintisiete indicadores o elementos de análisis, agrupados en cuatro grandes apartados: aspec- 
tos generales, contenidos, sistema de consulta, y página de resultados.

Todos los indicadores se pueden ponderar para la valoración de los servicios, ya que su presencia, ausencia y grado de desarrollo se pueden considerar valores objetivos en la evaluación de los sistemas, con la única excepción del indicador "coste", que solamente se ha incluido en la relación a título informativo.

Una cuestión importante a considerar es el proceso a seguir en la medición o aplicación de los indicadores, y más concretamente, si se tienen en cuenta o no aspectos cuantitativos. En los estudios que hemos realizado previamente (Abadal; Guallar 2008) no hemos optado por aplicar una puntuación como la que se puede ver en propuestas como la de Codina (2006), del 0 al 3, por ejemplo; sino que hemos señalado la valoración de los indicadores generalmente a niveles bajo, medio o avanzado. En el trabajo que aquí presentamos, señalamos las características de cada indicador y en la mayoría de los casos las condiciones que deben reunir para obtener una valoración alta, media o baja, y dejamos abierta la posibilidad de que se pueda aplicar a los mismos una puntuación numérica.

A continuación mostramos la relación de indicadores, y para cada uno de ellos:

- definición

- procedimiento o explicación de su uso y

- ejemplos de buenas prácticas (en algunos casos indicamos las url específicas de servicios o ejemplos)

\section{"Se proponen veintisiete indicadores agrupados en cuatro grandes apartados: aspectos generales, contenidos, sistema de consulta, y presentación de resultados"}

\section{A. Aspectos generales}

\section{A.1 Denominación}

El término que el diario otorga a su sistema o sistemas de consulta retrospectiva.

La denominación debe ser clara y fácilmente identificable por los usuarios que consultan un periódico digital.

"Hemeroteca" y "archivo" son las dos más utilizadas, con un cierto predominio para la primera de ellas. En cualquier caso, ambos términos son perfectamente

\begin{tabular}{|c|c|}
\hline Apartado & Indicador \\
\hline $\begin{array}{l}\text { A. } \\
\text { Aspectos } \\
\text { generales }\end{array}$ & $\begin{array}{ll}\text { A.1 } & \text { Denominación } \\
\text { A.2 } & \text { Ubicación del acceso a la hemeroteca } \\
\text { A.3 } & \text { Información sobre la hemeroteca } \\
\text { A.4 } & \text { Visibilidad } \\
\text { A.5 } & \text { Accesibilidad } \\
\text { A.6 } & \text { Coste }\end{array}$ \\
\hline $\begin{array}{l}\text { B. } \\
\text { Contenidos }\end{array}$ & $\begin{array}{ll}\text { B.1 } & \text { Colecciones disponibles } \\
\text { B.2 } & \text { Formatos disponibles } \\
\text { B.3 } & \text { Cobertura temporal }\end{array}$ \\
\hline $\begin{array}{l}\text { C. } \\
\text { Sistema } \\
\text { de } \\
\text { consulta }\end{array}$ & $\begin{array}{ll}\text { C.1 Tipos de consulta por palabra clave } \\
\text { C.2 } & \text { Lenguaje de consulta } \\
\text { C.3 Visualización de los índices } \\
\text { C. } 4 \text { Ajuste de relevancia } \\
\text { C. } 5 \text { Acotación temporal } \\
\text { C.6 Acotación en colecciones } \\
\text { C.7 Acotación en formatos } \\
\text { C.8 Acotación en campos del registro } \\
\text { C.9 Reutilización de estrategias de } \\
\text { búsqueda } \\
\text { C.10 Recuperación por navegación } \\
\text { (browsing) } \\
\text { C.11 Ayudas }\end{array}$ \\
\hline $\begin{array}{l}\text { D. } \\
\text { Página } \\
\text { de } \\
\text { resultados }\end{array}$ & 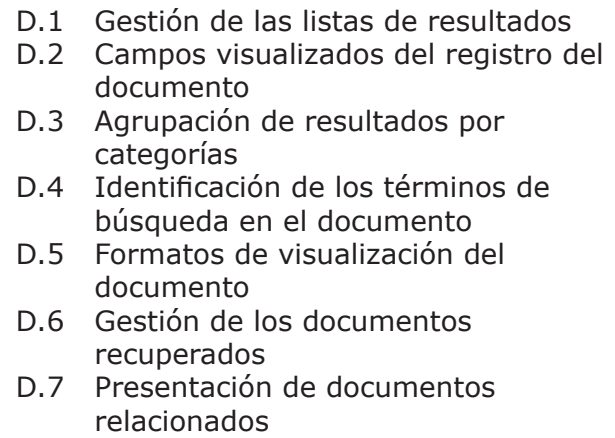 \\
\hline
\end{tabular}

Tabla 1. Indicadores para el análisis de hemerotecas digitales

identificables por parte de los usuarios. Por otro lado, en la página de inicio también se utiliza el término "búsqueda" o "buscar" para indicar el recuadro de texto para realizar las consultas.

\section{A.2 Ubicación del acceso a la hemeroteca}

Localización de la opción "hemeroteca" en la página de inicio del diario.

En general la prensa digital dispone de dos líneas de menú horizontales en la parte superior, una de ellas pensada para acceder temáticamente a los contenidos (secciones) y la otra línea que agrupa otro tipo de accesos (servicios, gráficos, versión impresa, etc.) entre los cuales, en muchos casos, se encuentra la hemeroteca. Por su parte, los recuadros de texto para la búsqueda siguen los patrones de las sedes web y son fácilmente visibles en la parte superior derecha de las páginas de inicio.

La ubicación en el primer nivel de los menús se encuentra por ejemplo en El mundo.es, El país.com, La vanguardia.es, o El periódico.com y hace relativamente fácil y directo el acceso al usuario (figura 1). En cambio es poco recomendable tener que ir a buscar en segun- 


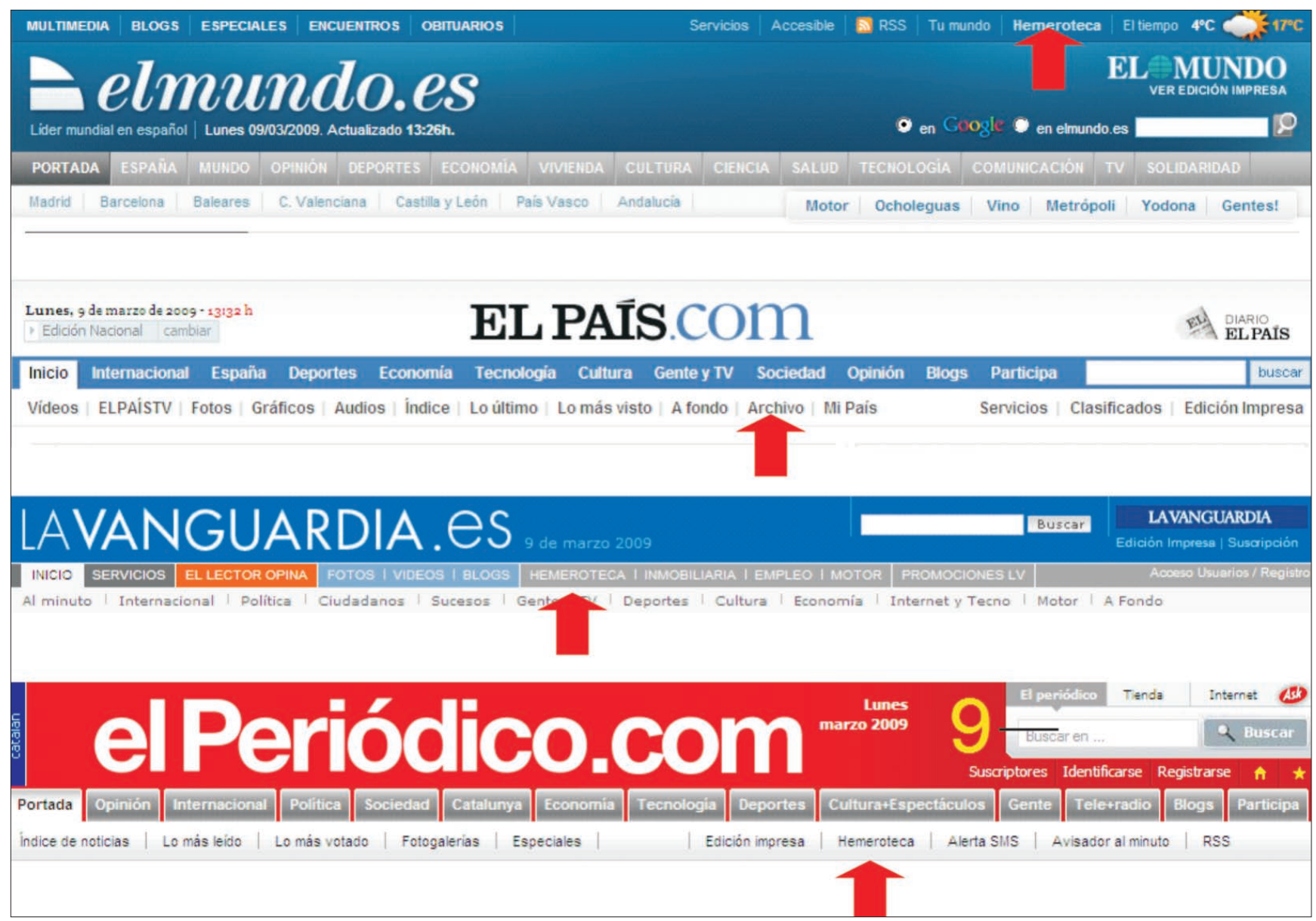

Figura 1. Ubicación del acceso al servicio de hemeroteca o archivo en la página de inicio de El mundo.es, El país.com, La vanguardia.es y El periódico.com

dos niveles de menús laterales poco visibles (Sport.es), o en primer nivel del menú lateral (ABC.es).

\section{A.3 Información sobre la hemeroteca}

Información general y explicaciones sobre diferentes aspectos de la hemeroteca: fondos, tecnología (programa utilizado), etc.

Se valora que los diarios ofrezcan al usuario una información suficiente para que éste sepa con claridad qué contenidos tiene, y cuál es el sistema de consulta existente.

Los diarios suelen proporcionar escasa o nula información sobre sus hemerotecas, por lo que en líneas generales este indicador no alcanza valores satisfactorios, salvo en algunas excepciones relacionadas siempre con aspectos concretos y que, en cualquier caso, satisfacen de manera parcial este indicador. Así, algunos diarios informan simplemente del nombre del programa utilizado como buscador (por ejemplo, El mundo.es utiliza Autonomy); otros medios informan de que tienen externalizado de manera total o parcial su servicio de búsqueda (ABC.es, La razón.es, El periódico.com confían las búsquedas de sus ediciones impresas a Mynews; $\mathrm{Li}$ bertad Digital y 20 minutos.es utilizan respectivamente los buscadores generalistas Yahoo y Google); y en los casos de hemerotecas históricas centenarias se muestra información variada en relación con su cobertura temporal (La vanguardia.es y El mundo deportivo.es)

\section{A.4. Visibilidad}

Presencia en internet de los archivos de prensa a partir del número de enlaces que apuntan a cada página en concreto.

Para el recuento se puede utilizar la instrucción "link:" de Google o preferentemente Yahoo Site Explorer service. La prensa digital dispone de una visibilidad muy alta, ya que son sedes web muy utilizadas. En el caso de las páginas de hemeroteca, no obstante, estos valores suelen ser mucho más modestos.

Los archivos de El mundo.es o El país.com son algunos de los que disponen de mayor número de enlaces, aunque los datos pueden variar si se utiliza Google o Yahoo.

http://www.google.es

http://es.siteexplorer.search.yahoo.com/siteexplorer

\section{A.5. Accesibilidad}

Facilidad que ofrece a cualquier tipo de usuario para acceder a sus contenidos. Se refiere al grado de cumplimiento de las normas de accesibilidad, que ha- 
cen posible que personas con distintos grados de discapacidad puedan consultar sitios web sin dificultades.

El W3C tiene publicadas una serie de pautas (Web, 2008) que desde diciembre de 2008 han pasado a la categoría de recomendaciones de este consorcio, cuyo cumplimiento posibilita que personas con distintas discapacidades puedan acceder a los contenidos de los sitios web. Este indicador afecta a toda la web y no tan sólo a la hemeroteca.

En general, los medios no acostumbran a incluir la indicación de página accesible, aunque en algunos casos, como El mundo.es o El país.com se pueden encontrar versiones "accesibles" de contenidos.

\section{A.6. Coste}

Condiciones de acceso gratuito o de pago de las hemerotecas. En este último caso, modalidades de pago existentes.

Ese indicador no se utilizará para la valoración de la hemeroteca, sino que se tiene en cuenta exclusivamente en el ámbito informativo, para conocer las condiciones de acceso a la información.

En la actualidad, y después de diferentes ensayos en las fórmulas gratuitas y/o de pago para el acceso a los contenidos retrospectivos, los diarios españoles se mueven entre dos tendencias:

- la gratuidad total: es el modelo hegemónico (Salaverría 2008, p 25), generalizando, es el sistema se- guido por los diarios nativos digitales, los procedentes de gratuitos impresos, los locales y regionales, y algunos grandes medios;

- el modelo mixto de contenidos de pago y gratuitos: seguido por algunos diarios con ediciones impresa y digital, en los que se cobra por la totalidad o una parte de las ediciones impresas en pdf, en diferentes fórmulas, desde la suscripción anual a la compra de ediciones o de documentos independientes.

\section{B. Contenidos}

\section{B.1 Colecciones disponibles}

Colecciones proporcionadas por la hemeroteca del diario: una única colección, dos (impresa y digital) u otras variables.

Se valora que los periódicos especifiquen con claridad las colecciones de que disponen y sus características, para no inducir a error o confusión en la consulta.

Un buen ejemplo es El mundo.es. Al entrar en la página de hemeroteca presenta la opción de buscar en El mundo.es (colección digital) o en El mundo (edición impresa) (figura 2). En este caso no se especifican las particularidades de ambos fondos como sería deseable, sin embargo, el lector ya conoce las diferencias por la experiencia previa de navegación en la web: el diario presenta dos webs diferenciadas, incluso en formato y diseño, para ambas colecciones.

http://www.elmundo.es/hemerotecal

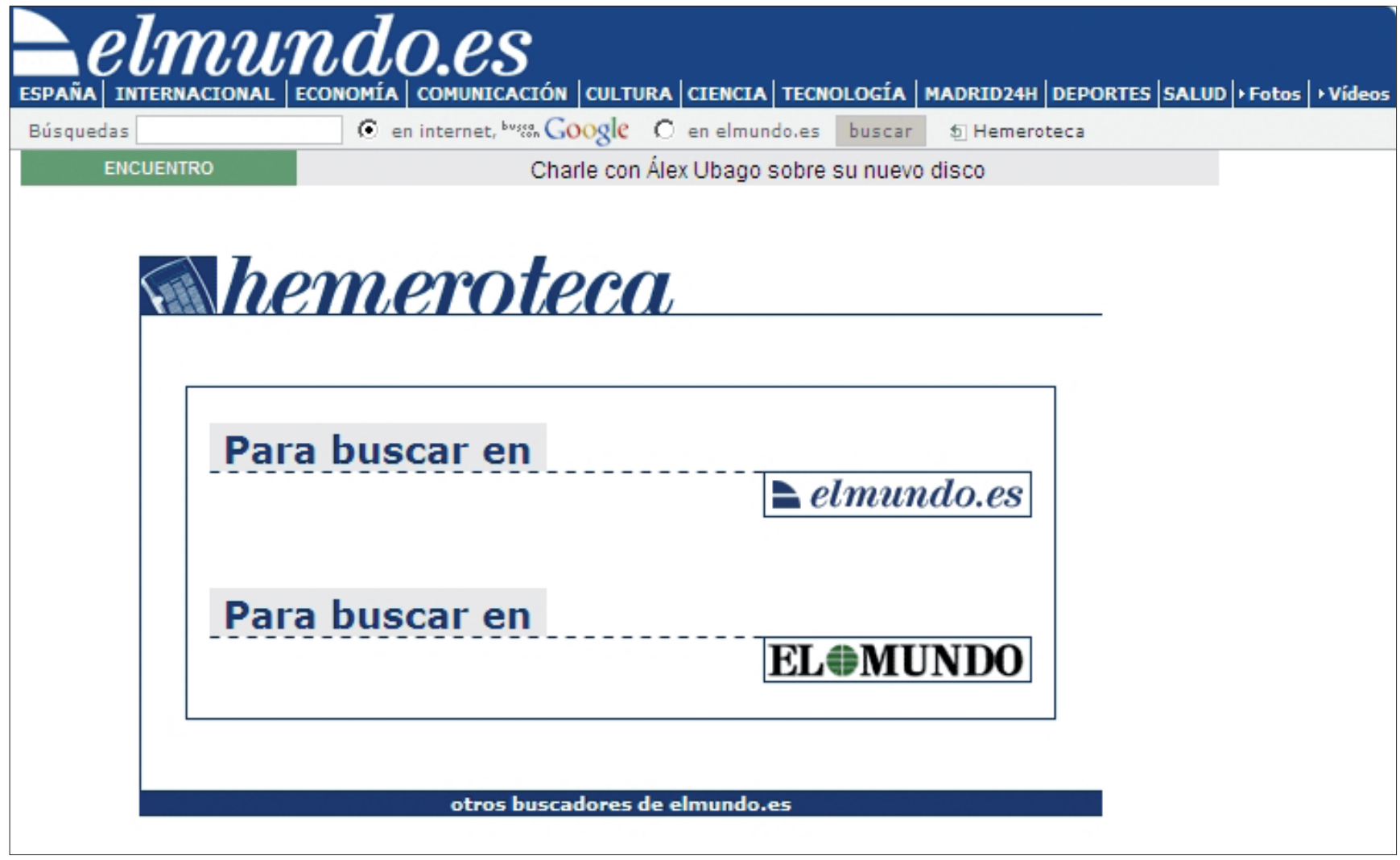

Figura 2. Colecciones digital e impresa en El mundo.es 


\section{B.2. Formatos disponibles}

Tipos de formatos existentes en el fondo documental del diario. Los más habituales, además de los textuales, son fotografías, gráficos, audio y vídeos.

Su presencia va pareja a la evolución de la prensa digital hacia el entorno multimedia. Es lógico que todos los contenidos que se proporcionan en la edición diaria también pasen a la colección retrospectiva. Se considera que un diario tiene valores altos en este indicador cuando además de contenidos textuales, contiene fondos específicos de fotografías, audio, vídeo y gráficos animados.

Aunque es una tendencia en ascenso bien visible en diversas cabeceras, algunos ejemplos de fondos multimedia destacados son los diarios El mundo.es o El país. com.

\section{B.3. Cobertura temporal}

Alcance temporal del fondo de la hemeroteca.

Se trata de uno de los indicadores fundamentales. El máximo cumplimiento lo tendrían aquellos diarios que proporcionan acceso en línea a la totalidad de su archivo. Cuando esto no es así, se debe valorar la proporción del fondo en línea en relación a la totalidad, y dentro de esta segunda posibilidad, que tenga un mínimo de cinco años de cobertura.

Entre los medios de comunicación impresos, hay muy pocos que ofrezcan el conjunto de sus contenidos desde su fundación. Destacan las hemerotecas centenarias de La vanguardia.es, desde 1881 y El mundo deportivo.es, desde 1906, que constituyen por su antigüedad dos de los archivos de diarios en línea más importantes del mundo (figura 3 ). Se debe citar así mismo El país.com, también disponible en su totalidad (desde 1976). Por otra parte, los diarios digitales nacidos en los últimos años están ofreciendo desde el inicio el acceso a todo el servicio de hemeroteca, por ejemplo, Soitu.es (desde diciembre de 2007) o Público.es (septiembre de 2007), aunque falta ver si esto se mantendrá en el futuro a medida que crezca la colección.

http://www.lavanguardia.es/hemeroteca/

http://www.elmundodeportivo.es/hemeroteca/index. html

\section{Sistema de consulta}

\section{C.1 Tipos de consulta por palabra clave}

Formas de consulta por palabra clave permitidas por el sistema.

Se valora que la hemeroteca ofrezca más de una opción de búsqueda para el usuario, y que disponga de al menos una con prestaciones avanzadas, siendo la situación ideal la de aquellos sistemas, como las bases de datos profesionales, que ofrecen tres opciones: simple, avanzada y profesional.

No hay casos de diarios en España con tres opciones de búsqueda. Sin embargo, un número destacado de periódicos sí contienen dos opciones de búsqueda, una más elemental y otra con funciones de búsqueda avanzada (en algunos casos externalizada), se llame o no así. Por lo tanto este indicador alcanza unos valores medios pero no altos. Los ejemplos, como se ha dicho, son numerosos. Véase por ejemplo ABC.es, La verdad. es, etc.

http://abc.mynewsonline.com/? method=query http://www.laverdad.es/murcia/archivo/busquedaavanzada

\section{C.2 Lenguaje de consulta}

Características del lenguaje de consulta: un lenguaje con prestaciones avanzadas debe incluir funciones de combinaciones de términos mediante la utilización de operadores booleanos, búsqueda de frases literales, operadores de proximidad y la utilización de paréntesis para aumentar las combinaciones.

Se considera que este indicador tiene un nivel medio si permite al menos la búsqueda con booleanos y la frase literal, y un nivel alto cuando incluye el resto de operadores y otras opciones, como la combinación de términos con paréntesis.

Los niveles más altos en este indicador (booleanos, de proximidad, literal y paréntesis) corresponden a $E l$ mundo.es y Vilaweb.cat

http://ariadna.elmundo.es/buscador/archivo. html? as $=1$

http://www.nosaltres.cat/www/cercar? consulta $=\&$ tipu $s=13 \% 2 C 9 \% 2 C 5 \% 2 C 201 \% 2 C 4103 \% 2 C 5235 \% 2 C 20$ $3 \% 2 C 4959 \& x=84 \& y=9$

\section{C.3. Visualización de los índices}

Visualización de los índices de los campos, especialmente los de autores, títulos y materias.

Una buena interfaz de consulta tiene que permitir esta visualización. Esto, que es frecuente en bases de datos especializadas, no acostumbra a estar presente en las hemerotecas.

Lo más frecuente es encontrar menús desplegables en algunos campos que sirven para enumerar los valores de la búsqueda y orientar a los usuarios. Sería el caso del campo "sección" (deportes, sociedad, internacional, etc.), "ediciones", "formato", etc. En cualquier caso, no obstante, no se trata de la extracción dinámica del contenido de los registros sino de una lista generada específicamente. Véase por ejemplo, el diario Sport.es

http://www.sport.es/buscador.asp 


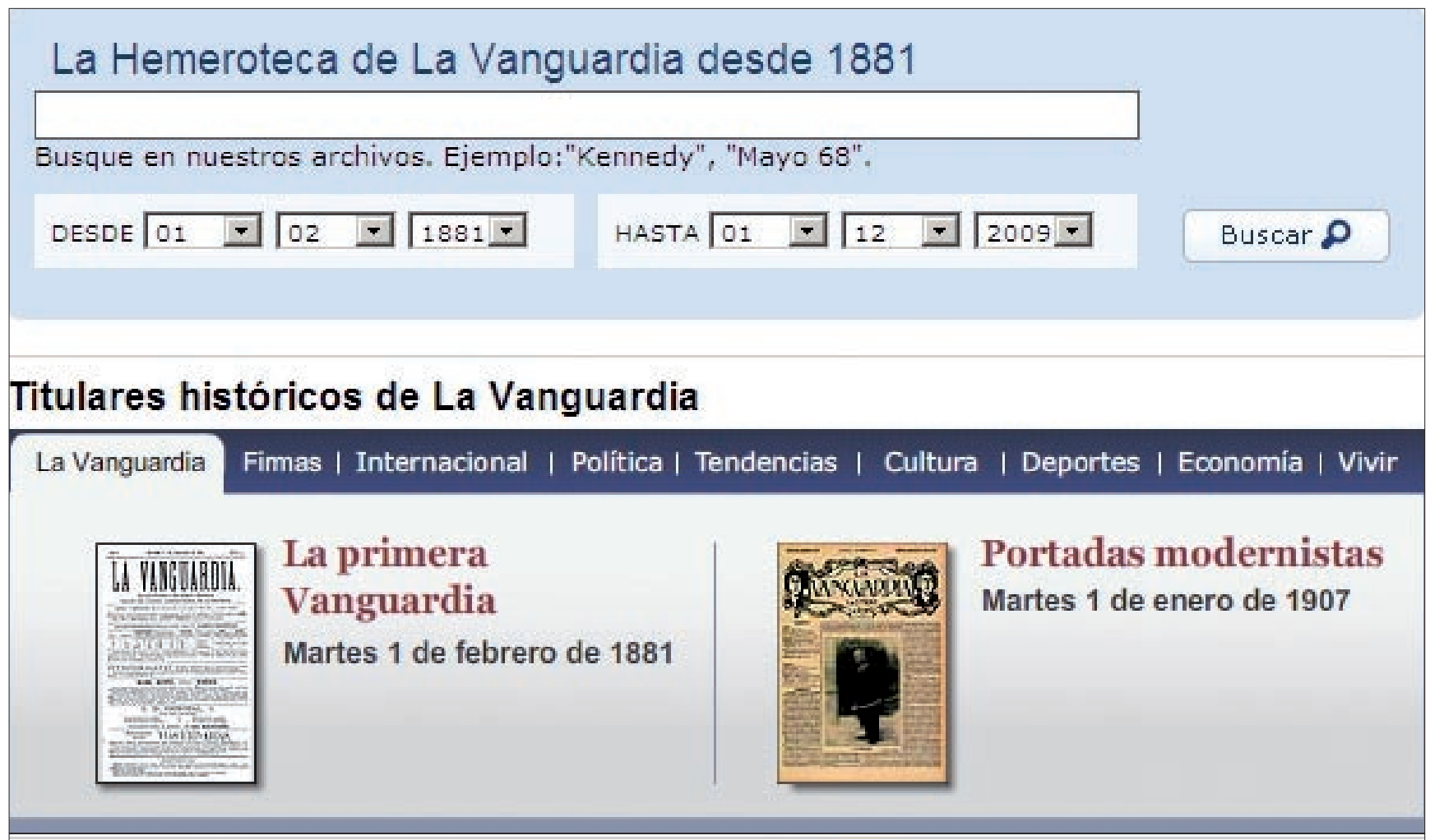

\section{TAL día COMO...}

\section{Viernes, 9 de marzo de 1923}
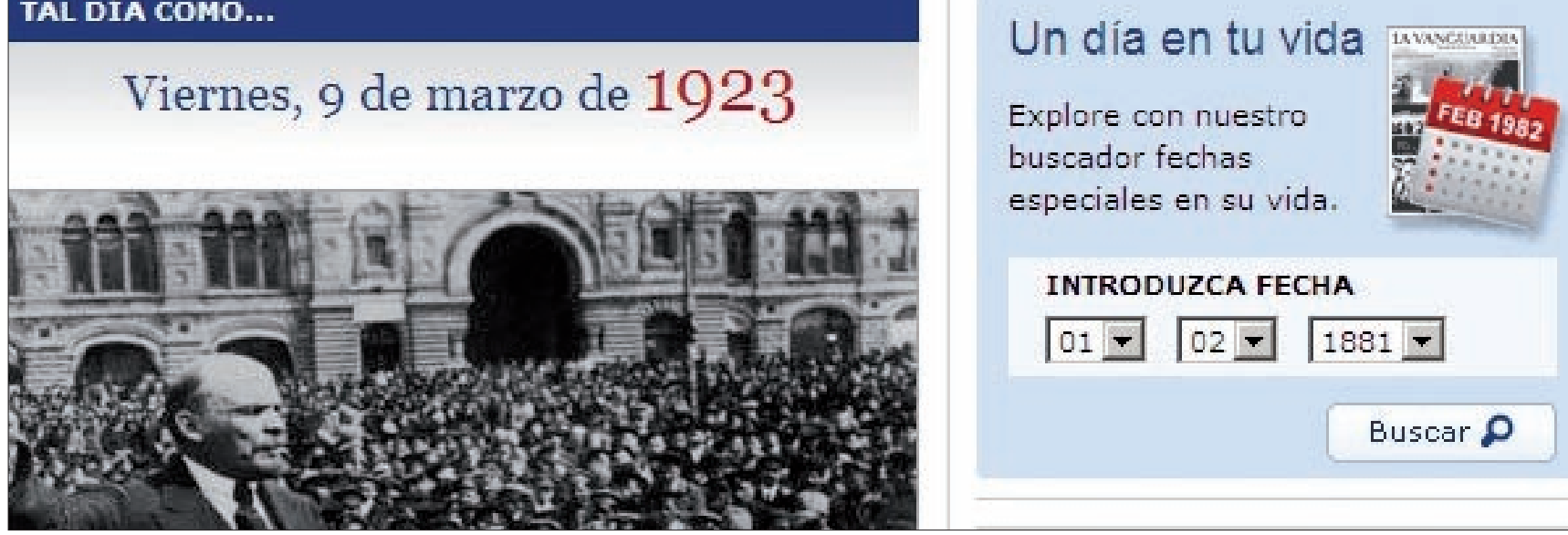

Figura 3. Hemeroteca centenaria de La vanguardia.es

\section{C.4 Ajuste de relevancia}

Posibilidad de definir el porcentaje de relevancia de los términos de la búsqueda para precisar más la consulta.

Esta función es propia de los sistemas profesionales de recuperación de la información, y consiste en el establecimiento de un porcentaje de relevancia en la consulta. Un porcentaje más alto ocasiona una búsqueda más precisa junto con una mayor probabilidad de silencio documental y un porcentaje de relevancia más bajo proporciona mayor exhaustividad en la recuperación, con más ruido.

Destaca en la prensa española El mundo.es, que tiene una opción de "relevancia mínima permitida" con un menú desplegable que permite delimitar la relevancia entre el 10 y el $95 \%$. http://ariadna.elmundo.es/buscador/archivo.html?as $=1$

\section{5 Acotación temporal}

Posibilidad de acotación temporal de la búsqueda.

La valoración es totalmente satisfactoria cuando el sistema proporciona diferentes posibilidades de definir la acotación temporal: menús desplegables con opciones del tipo: hoy, últimos tres días, última semana, último mes...; y delimitación exacta de fechas.

Buenos ejemplos son El país.com o La voz de Galicia.es. Algunos diarios tienen esta función pero solamente en alguna de sus colecciones, por ejemplo $E l$ periódico.com

http://www.elpais.com/archivo/buscador.html http://www.lavozdegalicia.es/hemeroteca/index.htm 


\section{http://periodico.mynewsonline.com/pdf/}

\section{C.6 Acotación en colecciones}

Capacidad de diferenciar entre búsqueda global o parcial en las colecciones disponibles, por ejemplo: en las diferentes secciones del diario, en suplementos, etc.

Se considera que cumple satisfactoriamente esta condición cuando se pueden realizar búsquedas parciales en todas las secciones del diario.

Buenos ejemplos son Sport.es (figura 4) o El país. com, con búsquedas parciales sobre un número importante de secciones o subsecciones.

http://www.sport.es/buscador.asp http://www.elpais.com/archivo/buscador.html

\section{C.7 Acotación en formatos}

Funciones de recuperación por formatos: texto, fotos, gráficos, vídeos, otros documentos...

La valoración de este indicador es totalmente satisfactoria cuando la hemeroteca del medio permite realizar consultas sobre el conjunto de formatos posibles en un medio digital.

Buenos ejemplos son El país.com, que posibilita la búsqueda por: cualquier formato, artículo o viñeta, fotografía, animación y gráfico, archivo descargable, audio y vídeo (figura 5); La vanguardia.es, que presenta la opción "formato" para buscar noticias, fotografía, vídeo, blog, galerías..., o As.com que facilita la consulta por audio, vídeo, fotografías animación/gráfico o cualquier formato.

http://www.elpais.com/archivo/buscador.html

http://buscador.lavanguardia.es/buscador/index. $x h t m l ? q=\&$ searchButton. $x=22 \&$ searchButton. $y=4$

http://www.as.com/busca/avanzada.html

\section{C.8 Acotación en campos del registro}

Capacidad de diferenciar entre búsqueda global o parcial en los campos del registro. Por ejemplo, en campo de título, autor, sección, etc.

Se considera que cumple satisfactoriamente esta condición cuando el usuario puede optar entre búsquedas globales o parciales al menos en tres campos diferentes.

Los diarios El país.com, As.com y Mundo deportivo.es son los que tienen más posibilidades de búsquedas parciales por campos: todo el artículo, titular y subtítulo, firma y cuerpo (los dos primeros), o cualquier parte, titular, epígrafe y autor (el último).

http://www.elpais.com/archivo/buscador.html http://www.as.com/busca/avanzada.html

http://www.elmundodeportivo.es/cercadormd/ CercadorMD?p_action=cercar\&p_collection $=$ noticiasmd\&p_frase $=\&$ cercamchome. $x=28 \&$ cercamchome. $y=14$

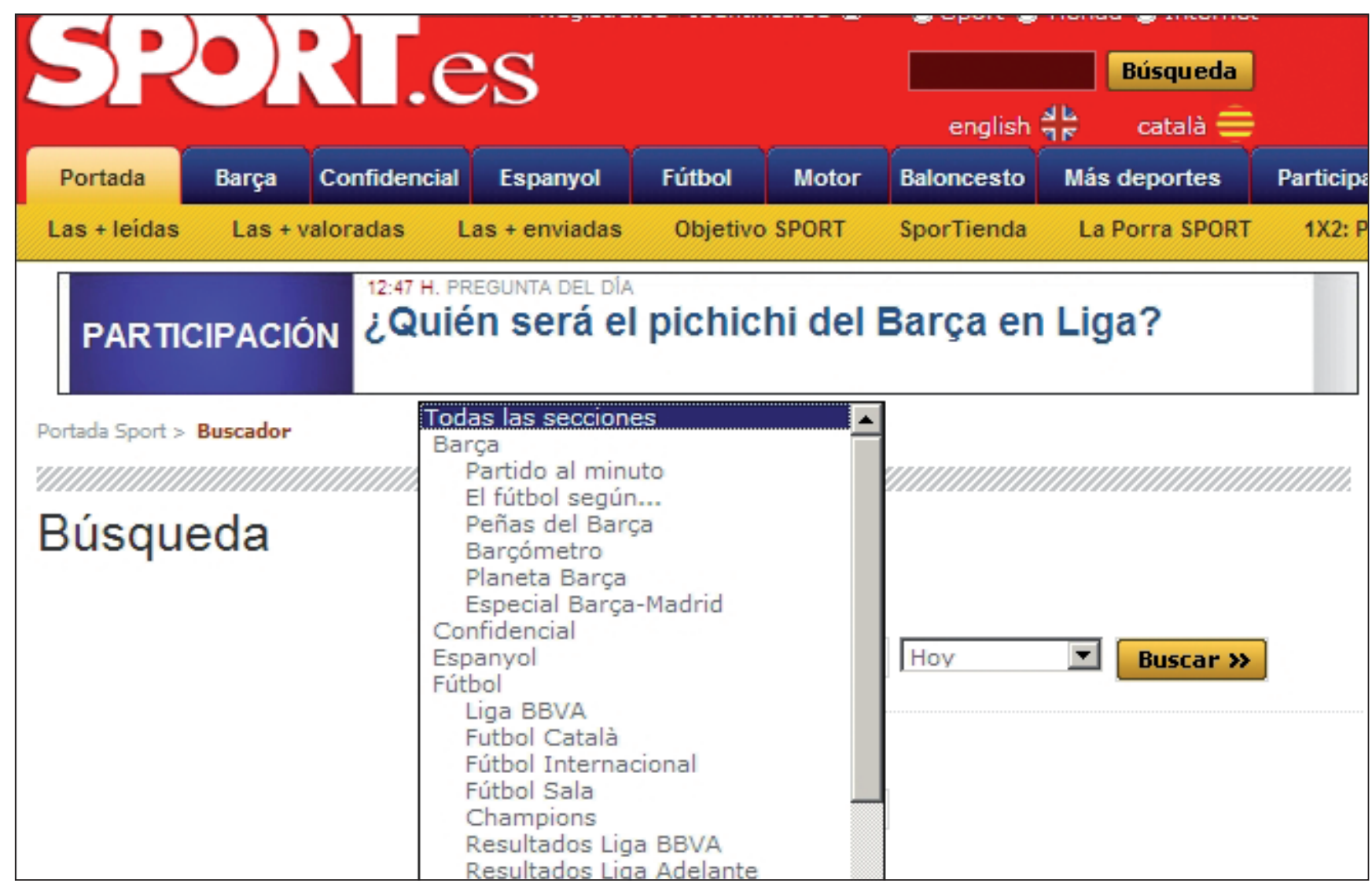

Figura 4. Búsqueda por secciones en Sport.es 


\section{ELPAİS COM Archivo}

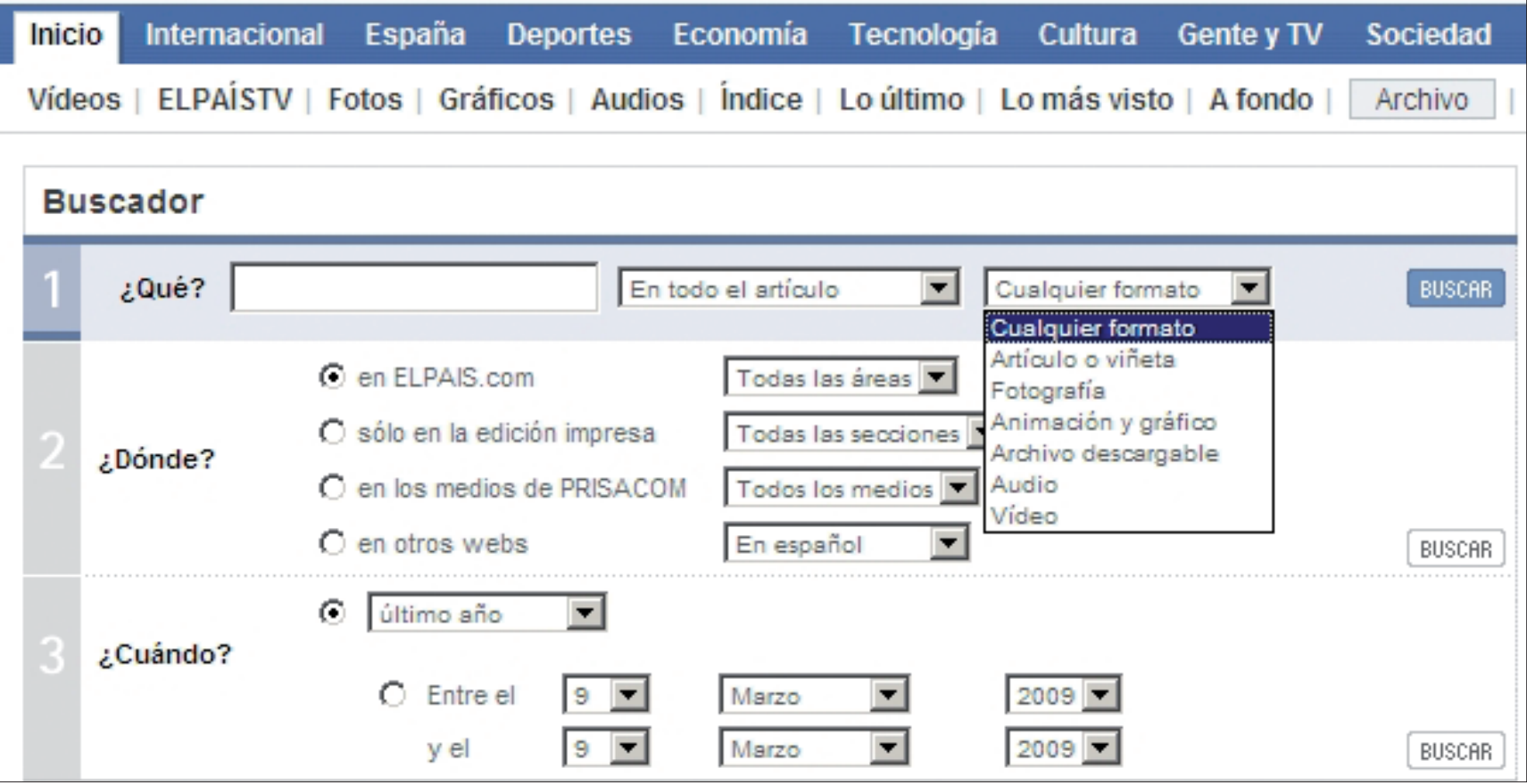

Figura 5. Búsqueda por formatos en El país.com

\section{C.9 Reutilización de estrategias de búsqueda}

Posibilidad de guardar la consulta o consultas anteriores, mediante un sistema de historial de búsquedas.

La valoración de este indicador es totalmente satisfactoria cuando se presenta al usuario la posibilidad explícita de reutilización de búsquedas anteriores, más allá de las opciones de guardar los términos de las búsquedas que permite el caché del navegador. La existencia de esta última función cumple este indicador solamente de manera parcial.

No hay ningún caso en la prensa española de cumplimiento satisfactorio de este indicador.

\section{C.10 Recuperación por navegación (browsing)}

Posibilidad de acceso al documento a partir de navegación por fecha de edición.

Se considera que cumple esta condición satisfactoriamente cuando el diario presenta un servicio de navegación por fechas de edición sobre el conjunto de contenidos del diario (no solamente sobre la portada, como en algunos casos) y sobre la totalidad de su fondo, y cumple esta condición en un nivel medio cuando ofrece una colección de un mínimo de cinco años de antigüedad.

Los casos más significativos son el acceso por fecha a las hemerotecas centenarias de La vanguardia.es (figura 3) y Mundo deportivo.es.

http://www.lavanguardia.es/hemerotecal http://www.elmundodeportivo.es/hemeroteca/index. html

\section{C.11 Ayudas}

Textos explicativos sobre la utilización del sistema de búsqueda.

La valoración de este indicador es totalmente satisfactoria cuando el texto se refiere explícitamente a las características del sistema de consulta y es una ayuda real al usuario en su utilización; no se consideran en este apartado comentarios informativos de tipo general muy básico o exclusivamente sobre las condiciones económicas de acceso a la información.

Algunos buenos ejemplos de ayudas a la búsqueda son las de los diarios ABC.es, El mundo.es o Vilaweb. cat.

http://www.abc.es/archivo/buscar.asp

http://ariadna.elmundo.es/buscador/archivo. html? as $=1$

http://www.nosaltres.cat/ajuda_cerca.php

\section{Página de resultados}

\section{D.1. Gestión de las listas de resultados}

Posibilidad de presentar diferentes opciones de gestión de las listas de resultados, por ejemplo, distintas ordenaciones de los registros (por relevancia o por fecha) o de presentar distintos listados con límite de registros.

Se considera que cumple este indicador satisfactoriamente cuando reúne las dos condiciones, y parcialmente, cuando cumple una de las dos. 
Es una función bastante extendida entre la prensa digital española; por ejemplo, se puede ver en $A B C$.es o La verdad.es.

http://abc.mynewsonline.com/index.php http://www.laverdad.es/murcia/archivo/busquedaavanzada

\section{D.2. Campos visualizados del registro del documento}

Número de campos que se muestran en cada registro y cuáles son (autor, título, fecha, sección, etc.).

La valoración de este indicador es satisfactoria si el sistema proporciona un mínimo de cuatro campos, y al menos tres de ellos han de ser autor, título y fecha. Los valores más altos en este indicador se sitúan sobre los 7 campos en el registro.

Están bien representados en este indicador $A B C$.es, El mundo.es o El país.com.

http://abc.mynewsonline.com/index.php http://ariadna.elmundo.es/buscador/archivo. html? as $=1$

http://www.elpais.com/archivo/buscando.html

\section{D.3. Agrupación de resultados por categorías}

Presentación de agrupaciones en la lista de resultados: por tema, por formato, por tipo de documento, etc.

Se trata de un aspecto especialmente útil cuando se presentan muchos registros al usuario, como acostumbra a ser el caso de las hemerotecas. Las agrupaciones las realiza de forma automática el motor de búsqueda.

No se encuentran ejemplos en hemerotecas de diarios españoles, como los que se pueden apreciar en el sector de la información de prensa, en bases de datos como Lexis Nexis o servicios de agregación de noticias como iMente.

http://www.lexisnexis.com/

http://www.imente.com/

\section{D.4. Identificación de los términos de búsqueda en el documento}

Función para ver resaltados los términos de la consulta en los resultados que muestra el sistema, en el registro del documento o en el documento final.

La importancia de este indicador radica en la posibilidad de apreciar la situación o posición que tienen las palabras consultadas dentro del documento recuperado. La valoración de este indicador es satisfactoria cuando los términos aparecen resaltados en el registro o en el documento final, pero en el primer caso, se debe precisar que la extensión en caracteres del campo de texto debe ser la suficiente para poderse apreciar (a partir de un mínimo de tres o cuatro líneas de texto). Por ejemplo, algunos diarios cuentan con esta función, pero el campo de texto se reduce a una o dos líneas, con lo que se limita mucho la identificación de los términos.

Un buen ejemplo es el diario El país.com, que en las búsquedas sobre su edición impresa recupera registros en los que los términos de la consulta aparecen resaltados en campos de texto de hasta 10 líneas (figura 6).

\section{D.5. Formatos de visualización de un mismo docu- mento}

Existencia de más de un formato de presentación de un documento (en un documento textual: html, pdf, etc.).

Se considera que cumple satisfactoriamente esta función cuando el usuario puede acceder a diferentes formas de visualización del mismo documento, no sólo con la dualidad html o pdf en el caso de la versión impresa, sino también si se dispone de versiones para lectura en diferentes dispositivos, como pda y teléfonos móviles.

Un buen ejemplo es El país.com, cuyos documentos de texto tienen 4 opciones de visualización: versión en html (tal como aparece en la web), texto accesible o sólo texto (el texto sin imágenes), versiones para pda/ psp y móvil, y pdf (para la edición impresa). Véase por ejemplo al final de una noticia de este diario, el apartado "Otras ediciones".

http://www.elpais.com/articulo/espana/Bermejo/ dimite/acosado/PP/jueces/criticado/companeros/ elpepiesp/20090224elpepinac_1/Tes

\section{D.6. Gestión de los documentos recuperados}

Existencia de diversas funciones para la gestión de los documentos recuperados, por ejemplo: enviar por correo electrónico, imprimir, guardar, obtener información sobre su uso (estadísticas), valorar o comentar la noticia, compartir (envío del documento a webs sociales), etc.

Se considera que cumple satisfactoriamente este indicador cuando presenta un mínimo de cinco opciones diferentes de gestión de los documentos de las señaladas en el párrafo anterior.

En la actualidad, buena parte de los diarios online están cumpliendo satisfactoriamente esta función. Pueden verse ejemplos de noticias en 20 minutos.es, Avui. cat, El periódico.com...

http://www.20minutos.es/

http://www.avui.cat/

http://www.elperiodico.com/

\section{D.7. Presentación de documentos relacionados}

Posibilidad de recuperación de documentos que guardan relación con los obtenidos en la búsqueda, tanto del fondo del propio diario como de fuentes externas. 


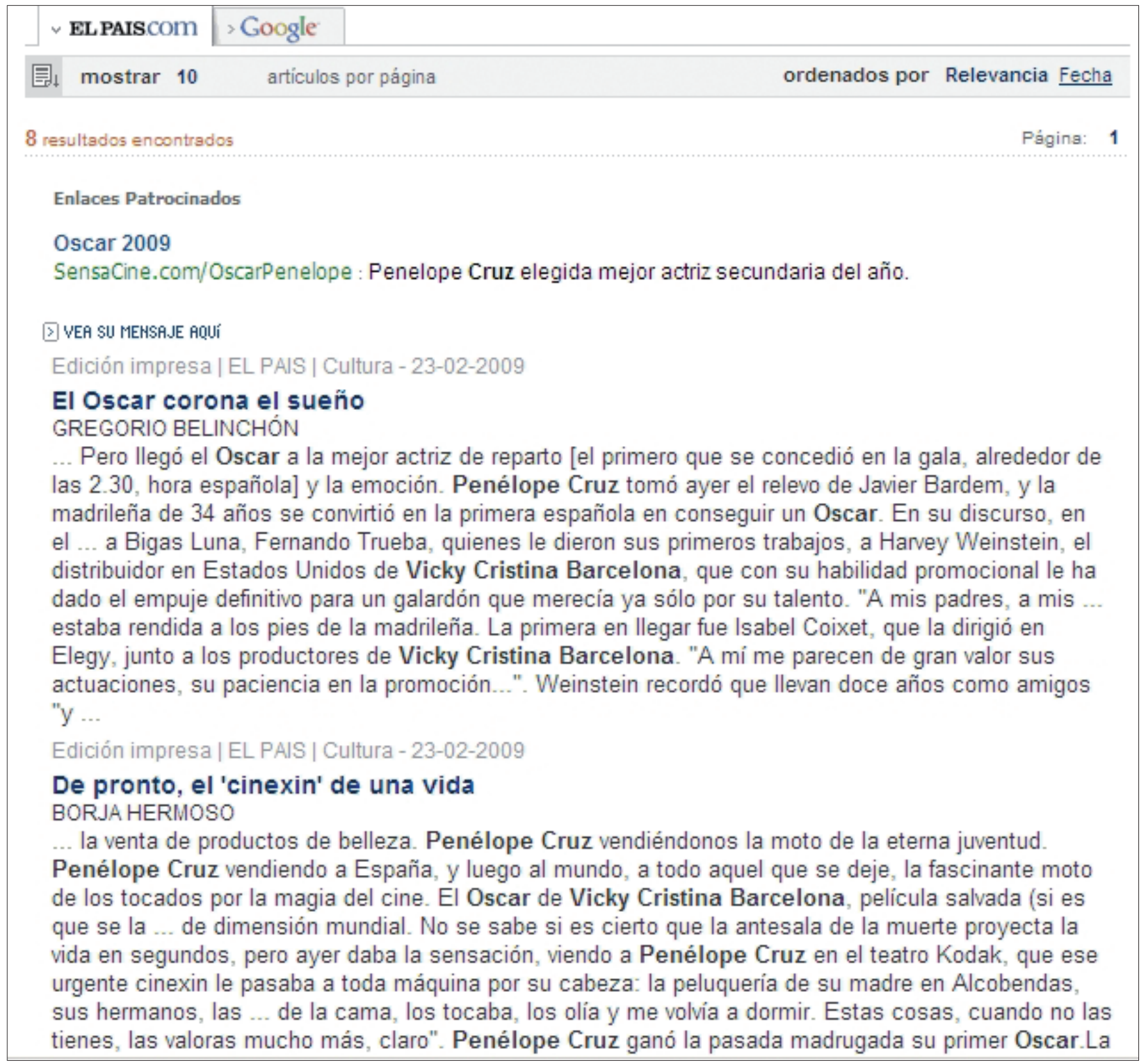

Figura 6. Pantalla de resultados de la búsqueda "Penélope Cruz", "Oscar", "Vicky Cristina Barcelona" en El país.com, en la que se puede apreciar la identificación de los términos de la consulta.

Se considera que cumple satisfactoriamente este indicador cuando el diario presenta documentos relacionados con la noticia recuperada, tanto de la fuente propia como de fuentes externas, y que lo cumple sólo parcialmente cuando muestra documentos relacionados del propio medio.

Son numerosos los cibermedios que muestran noti-

\section{"En cobertura temporal destacan La vanguardia.es y Mundo deportivo.es, en lenguaje de consulta El mundo.es y Vilaweb.cat, en acotación en colecciones Sport.es y El país.com"}

cias relacionadas, pero casi siempre del propio medio, por lo que la gran mayoría no cumplen este indicador de manera total al no mostrar noticias de otras fuentes. Entre las excepciones se pueden citar El país.com y El mundo.es -si bien en este último diario no en todas las informaciones- que sí enlazan con otros medios de comunicación y otras webs (figuras 7 y 8 ).

\section{Conclusiones}

El interés del establecimiento de indicadores radica en su utilidad para realizar evaluaciones de hemerotecas digitales. Dado que su número va en aumento será cada vez más conveniente que los profesionales de la documentación periodística así como los de bibliotecas y otros servicios de información puedan establecer criterios de selección que sirvan tanto para llevar a cabo 
proyectos de este tipo como para orientar a los usuarios en el uso de hemerotecas digitales para la consulta retrospectiva de información de prensa.

El listado de indicadores que se presenta se ha basado en la revisión de la bibliografía de evaluación de recursos web, bases de datos y hemerotecas de prensa, y se ha testado previamente en análisis de diarios de España y Catalunya. El énfasis se ha puesto en el análisis del sistema de consulta y de la página de resultados, sin olvidar otros aspectos más generales y de contenidos.

Sin pretender realizar en este texto un estudio exhaustivo sobre una serie concreta de diarios, la aplicación de los indicadores en una muestra de diarios españoles sí ha permitido seleccionar ejemplos de buenas prácticas en la mayoría de los casos, que pueden servir como referencia para otros medios, así como apreciar aquellos elementos que presentan valores negativos o insuficientes.

Así, en buena parte de los indicadores se han podido ver algunos casos de diarios que alcanzan valores altos, por ejemplo, en cobertura temporal La vanguardia.es o Mundo deportivo.es, en lenguaje de consulta El mundo. es o Vilaweb.cat, en acotación en colecciones Sport.es o El país.com, o en formatos de visualización de documentos El país.com; y por otra parte, en algunos indicadores, no se han encontrado ejemplos de cumplimiento satisfactorio. En estos últimos, por lo tanto, la prensa digital española todavía debe mejorar mucho; por ejemplo, en la reutilización de estrategias de búsqueda o en la agrupación de resultados por categorías.

\section{"En algunos indicadores, como la reutilización de estrategias de búsqueda o la agrupación de resultados por categorías, no se ha encontrado ningún ejemplo de cumplimiento satisfactorio"}

La utilización de estos indicadores en estudios de evaluación de muestras de diarios concretas puede permitir establecer diagnósticos de la situación de las hemerotecas digitales del sector estudiado y puede dar lugar a rankings de medios en relación a la calidad de sus servicios de consulta de información retrospectiva.

\section{Notas}

1.- Se han realizado dos estudios sobre muestras de los diarios de más difusión de ámbito español y catalán respectivamente, el primer trabajo inédito y el segundo disponible en Abadal y Guallar, 2008. Las listas de medios se obtuvieron cruzando los primeros resultados de las mediciones de $O J D$ y de EGM. Estas son:
- 20 minutos.es, ABC.es, As.com, Libertad digital.com, Marca.com, El mundo.es, El país.com, El periódico.com, Periodista digital.com, Sport.es, La vanguardia.es, La verdad.es.

- Avui.cat, El debat.cat, E-noticies.com, La malla.net, El mundo deportivo.es, Nació digital.com, Osona.com, El periódico.cat, Racó català.cat, Sport.es, La vanguardia.es, Vilaweb.cat.

\section{Bibliografía}

Abadal, Ernest. "Elementos para la evaluación de interfaces de consulta de bases de datos". El profesional de la información, 2002, septiembre-octubre, v. 11, n. 5 , pp. 349-360.

http://www.elprofesionaldelainformacion.com/contenidos/2002/septiembre/3.pdf

Abadal, Ernest; Guallar, Javier. "Les hemeroteques digitals de la premsa catalana: anàlisi dels diaris catalans de més difusió". En: Jornades Catalanes de Documentació (11es: Barcelona, 22-23 maig 2008). Barcelona: COBDC, 2008. pp. 149-162. http://eprints.rclis.org/archive/00013686/01/ jornades2008_guallar-abadal_hemeroteques_diaris.pdf

Armañanzas, Emy; Díaz-Noci, Javier; Meso-Ayerdi, Koldo. El periodismo electrónico. Información y servicios multimedia en la era del ciberespacio. Barcelona: Ariel, 1996, 249 p

Armentia-Vizuete, José-Ignacio et al. El diario digital: análisis de los contenidos textuales, aspectos formales y publicitarios. Barcelona: Bosch, 2000 .

Auer, N. J. Evaluating internet information.

http://www.lib.vt.edu/research/evaluate/evaluating.html

Cabrera-González, Má-Ángeles. La prensa “online”. Los periódicos en la $w w w$. Barcelona: CIMS, 2000.

Codina, Lluís. "Evaluación de recursos digitales en línea: conceptos, indicadores y métodos". Revista española de documentación científica, 2000, enero-marzo, v. 23, n. 1, pp. 9-44.

Codina, Lluís. Metodología de análisis y evaluación de recursos digitales en línea (v. 2006). Barcelona: UPF. Área de Biblioteconomía y Documentación. Dep. Periodismo y Comunicación Audiovisual, 2006, 56 pp. http://www.lluiscodina.com/metodos/metodos2006.doc

Cowen, $\mathbf{N}$. "The future of the British broadsheet newspaper on the world wide web", Aslib Proceedings, 2001, v. 53, n.5, pp.189-200

Díaz-Noci, Javier; Meso-Ayerdi, Koldo. "Desarrollo del periodismo electrónico". El Profesional de la información, 1998, v. 7, n. 12.

http://www.elprofesionaldelainformacion.com/contenidos/1998/diciembre/ desarrollo_del periodismo_electronico.html

Domingo, David. Periodisme digital a Catalunya: radiografia de 445 webs informatius. Barcelona: Col-legi de Periodistes de Catalunya, 2004.

Fuentes-i-Pujol, M.-Eulàlia; González-Quesada, Alfons. "La prensa española en internet. Análisis de los servicios de valor añadido". En: Jornadas Españolas de Documentación Automatizada (6as: Valencia: 1998), Valencia: Federación Española de Sociedades de Archivística, Biblioteconomía y Documentación, pp. 281-292.

García-Gómez, Juan-Carlos; González-Olivares, José-Luis. “Aproximación a la evaluación cuantitativa de los sistemas de recuperación de información de la prensa en internet: exhaustividad y precisión". SCIRE, 2001, v. 7 , n. 1 , pp. $143-152$

Guallar, Javier. "Prensa digital en 2006". Anuario ThinkEpi 2007, Barcelona: EPI SCP, 2006, pp. 106-117.

http://eprints.rclis.org/archive/00008388/01/AnuarioThinkEPI2007-Guallar-Prensa-digital-en-2006.pdf

Hofman, Paul; Worsfold, Emma. Selection criteria for quality controlled information gateways. Last updated: 17 May, 1999. DESIRE-RE 1004 http://www.ukoln.ac.uk/metadata/desire/quality/

Jiménez, Àngels. "Hemerotecas de pago en la prensa digital española". El profesional de la información, 2003, v. 12, n. 6, pp. 473-474.

Jiménez, Àngels; González, Alfons; Fuentes, M.-Eulàlia. "Las hemerotecas digitales de la prensa en internet". El profesional de la información, 2000, v. 9, n. 5, pp. 15-24

http://www.elprofesionaldelainformacion.com/contenidos/2000/mayo/2.pdf 


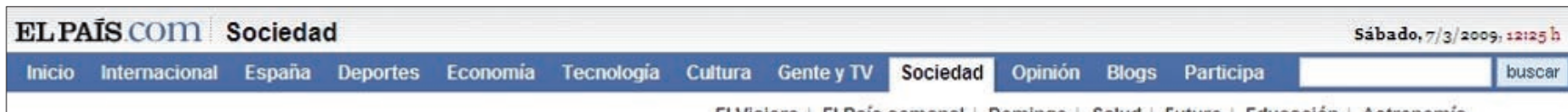

El Viajero | El Pais semanal | Domingo | Salud | Futuro | Educación | Astronomia

\section{EN DIRECTO}

Sigue el encuentro de la Copa Davis de tenis entre Ferrer y Djokovic

ELPAIS. com > Sociedad

\section{La expansión tecnológica no termina con la brecha digital}

Un informe de la ONU revela enormes diferencias mundiales, sobre todo en acceso a Internet

EFE - Ginebra - 02/03/2009

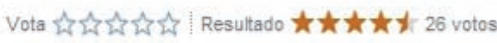

Comentarios - 5 是

La penetración de las tecnologías de la información y la comunicación (TIC) a nivel mundial sigue imparable, aunque de forma desequilibrada, con 4.000 millones de suscripciones a la telefonía móvil, 1.300 millones a líneas fijas y cerca de un cuarto de la población que utiliza Internet.

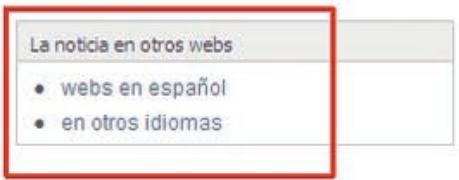

industrializados y en desarrollo".

Según estadísticas de finales de 2008 , se ha registrado un claro cambio de tendencia de la telefonía fija a la móvil, con tres veces más de suscripciones de este último tipo con

Así lo revelan los datos publicados hoy por la Unión Internacional de Telecomunicaciones (UIT), una agencia técnica de la ONU, que recalca que pese al alto crecimiento del sector "persisten
grandes diferencias entre regiones y entre países pese al alto crecimiento del sector "persisten
grandes diferencias entre regiones y entre países

foniagia la movil, con tres veces mas de suscripciones de este úlimo tipocon

7 resultados encontrados

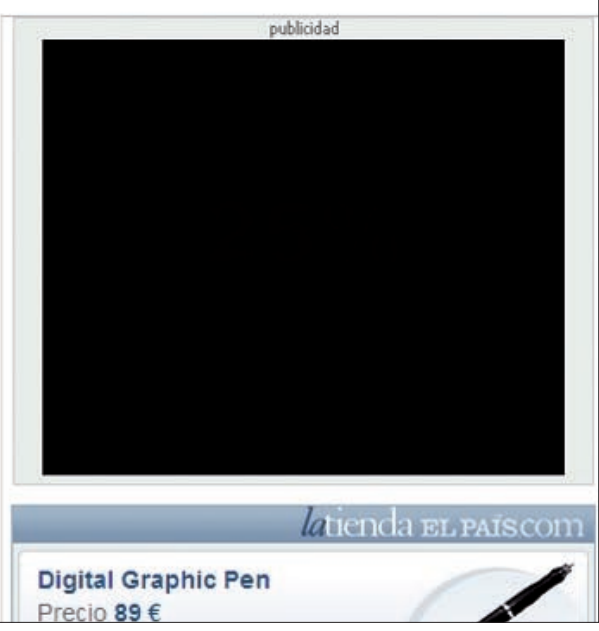

Página: 1

Enlaces Patrocinados

Vuelos con descuento

www.terminalA.com : Personal, para cada viaje Sin comisión aerea, jvuela!

[D. VEA SU MEHSA.JE RQUÍ

\section{CADENA SER}

\section{La expansión tecnológica no termina con la brecha digital}

La expansión tecnológica no termina con la brecha digital Un informe de la ONU revela enormes diferencias mundiales, sobre todo en acceso a Internet

\section{SOTU.ES}

\section{Sí, esto es una cámara}

Sí, esto es una cámara Pequeñas cámaras que hacen fotos con más calidad que las compactas actuales y que filman mejor que las videocámaras domésticas. Esta ha sido la gran tendencia que se ha visto en la PMA 2009, la feria de fotografia que acaba de terminar en Las Vegas ...

\section{LA VANGUARDIA}

\section{El $60 \%$ de los hogares españoles aún carece de conexión a internet}

El $60 \%$ de los hogares españoles aún carece de conexión a internet La Asociación para la Investigación de Medios de Comunicación alerta de la "brecha digital ...

\section{LA VANGUARDIA}

\section{El $60 \%$ de los hogares españoles aún carece de conexión a internet}

El $60 \%$ de los hogares españoles aún carece de conexión a internet La Asociación para la Investigación de Medios de Comunicación alerta de la "brecha digital ...

Figuras 7 y 8 . En el ejemplo, las noticias relacionadas con el documento obtenido en El país.com son informaciones de otros medios: La vanguardia.es, Soitu.es y Cadena Ser. 
Jiménez, Àngels; González, Alfons; Fuentes, M.-Eulàlia. "Gestió documental de la informació en els serveis de valor afegit de la premsa espanyola a internet". En: 7es Jornades Catalanes de Documentació. Les biblioteques $i$ els centres de documentació al segle XXI: peça clau de la societat de la informació. Barcelona, 4-6 novembre 1999. Barcelona: Col-legi Oficial de Bibliotecaris-Documentalistes de Catalunya, pp. 405-417. http://www.cobdc.org/jornades/7JCD/18.pdf

Jiménez, Marina; Ortiz-Repiso, Virginia. Evaluación y calidad de sedes web. Gijón: Trea, 2007.

Longo, Brunilla. "Gli archivi dei giornali online". Biblioteche oggi, 2006, vol 24 , n. 1, p. 9-21.

López-Carreño, Rosana. "Análisis taxonómico de los portales periodísticos españoles”. Anales de documentación, 2004, v. 7, pp. 123-140. http://www.um.es/fccd/anales/ad07/ad0708.pdf

López-García, Guillermo (ed.). Comunicación local y nuevos formatos periodísticos en internet: cibermedios, confidenciales y weblogs. Valencia: Servei de Publicacions de la Universitat de València, 2008. http://www.cibermediosvalencianos.es/ComunicacionLocal.pdf

Marchionini, Gary. Information seeking in electronic environments. Cambridge: Cambridge University, 1995.

Martínez-Rubio, Rosa. "La recuperación de la información en los periódicos digitales valencianos”. En: López García, Guillermo. Comunicación local y nuevos formatos periodísticos en internet: cibermedios, confidenciales $y$ weblogs. Valencia: Servei de Publicacions de la Universitat de València, 2008

http://www.cibermediosvalencianos.es/comloc/Martinez.pdf

Morville, P.; Rosenfeld, L. Information architecture for the world wide web. 3r ed. Sebastopol (Calif.) [etc.]: O’Reilly, 2006.

Nielsen, Jacob. Usabilidad: diseño de sitios web. Madrid [etc.]: Prentice Hall, 2000.
Nielsen, Jacob; Loranger, Hoa. Usabilidad: prioridad en el diseño web. Madrid: Anaya Multimedia, 2006.

Rodríguez-Yunta, Luis; Giménez-Toledo, Elea. "Más allá de la usabilidad: características mínimas exigibles para las interfaces de bases de datos web". BiD: textos universitaris de biblioteconomia i documentació, 2004, desembre, n. 13

http://www.ub.es/bid/13rodri2.html

Salaverría, Ramón (coord.). Cibermedios. El impacto de internet en los medios de comunicación en España. Sevilla: Comunicación Social ediciones y publicaciones, 2005 .

Salaverría, Ramón. "La investigación sobre ciberperiodismo en España: tendencias, resultados y perspectivas". En: López García, Guillermo. Comunicación local y nuevos formatos periodísticos en internet: cibermedios, confidenciales y weblogs. Valencia: Servei de Publicacions de la Universitat de València, 2008.

http://www.cibermediosvalencianos.es/comloc/Salaverria.pdf

Shneiderman, Ben; Byrd, Don; Croft, W.-Bruce. "Clarifying search: a user-interface framework for text searches”, D-Lib Magazine, January 1997

www.dlib.org/dlib/january97/retrieval/01 shneiderman.html

Web Content Accessibility Guidelines (WCAG) 2.0: W3C Recommendation, 11 December 2008

http://www.w3.org/TR/2008/REC-WCAG20-20081211/

Javier Guallar, Ernest Abadal, Universitat de Barcelona, Facultat de Biblioteconomia i Documentació. jguallar@gmail.com abadal@ub.edu

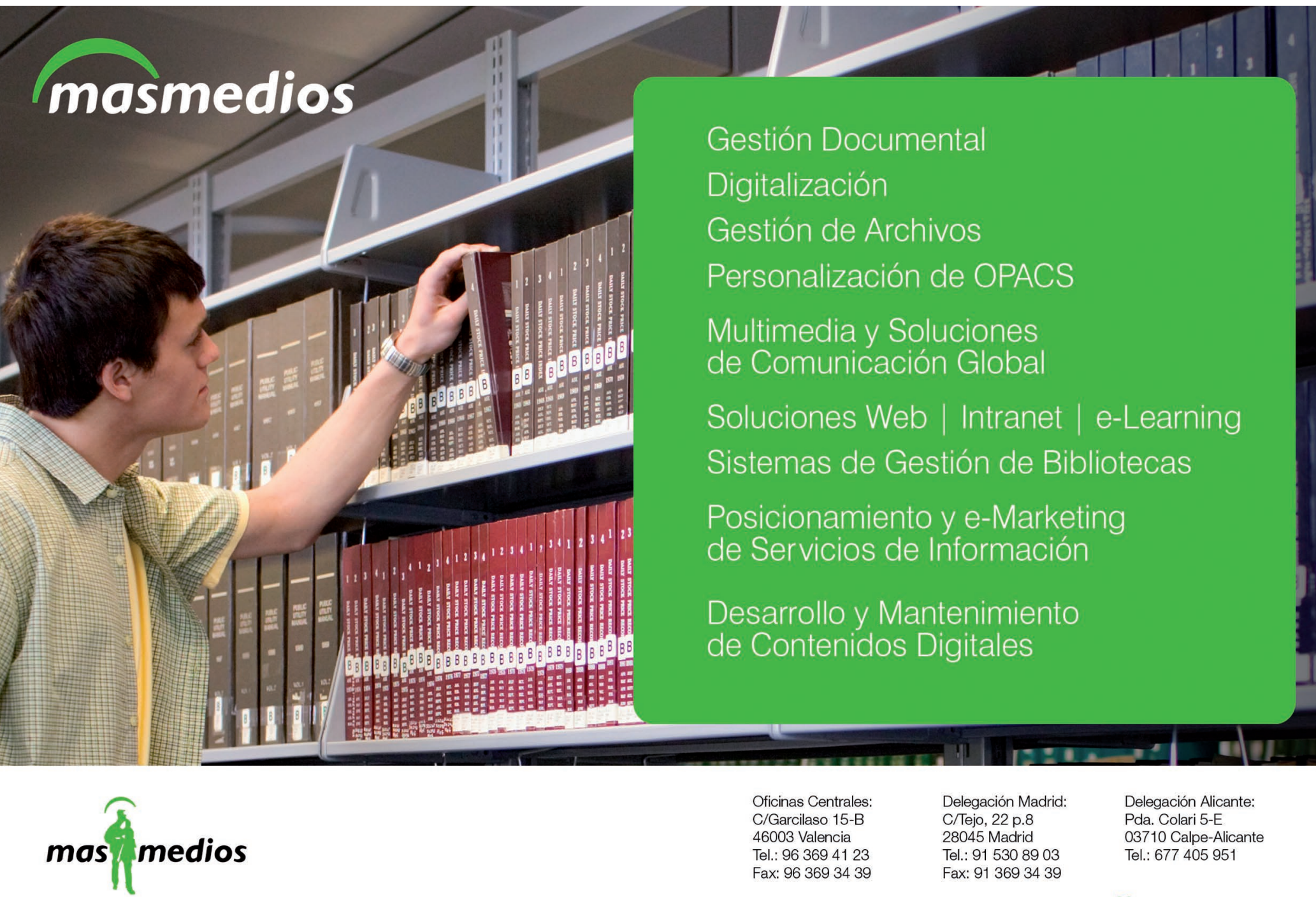

